\title{
Quatro temas fundamentais do pensamento neoconservador em política externa
}

\author{
Four basic themes of neoconservative thougt on foreign policy
}

CARLOS GUSTAVO POGGIO TEIXEIRA*

Rev. Bras. Polit. Int. 50 (2): 80-96 [2007]

\section{Introdução}

Os ataques terroristas de 11 de setembro de 2001, quando a administração de George W. Bush não havia sequer completado seu primeiro ano, colocaram o neoconservadorismo em destaque nos debates a respeito da política externa dos Estados Unidos.

No entanto, a quantidade de análises jornalísticas produzidas sobre esse tema revelou-se inversamente proporcional aos estudos acadêmicos dedicados a ele. O objetivo do presente artigo, adaptado de uma pesquisa mais ampla feita por este autor sobre o assunto ${ }^{1}$, é oferecer um panorama geral daquilo que se identifica como os quatro temas fundamentais de política externa do pensamento neoconservador e, dessa forma, contribuir para um melhor entendimento acerca do que, afinal, trata o neoconservadorismo.

Logo, não se propõe aqui oferecer uma crítica ao neoconservadorismo, nem tampouco analisar suas conseqüências políticas, mas sim tentar apresentar qual a visão de mundo oferecida por essa corrente de pensamento, a partir do ponto de vista de seus participantes.

Primeiramente, é importante destacar que, assim como em outras correntes de pensamento, não se pode atribuir àqueles identificados como neoconservadores uma coesão absoluta em termos de posições com relação à política externa dos Estados Unidos.

Dessa maneira, a escolha dos tópicos apresentados nesse artigo buscou um determinado nível de generalização, visto que quanto mais se particularizarem e

\footnotetext{
* Mestre em Relações Internacionais pela Pontifícia Universidade Católica de São Paulo - PUC-SP (cgpteixeira@ gmail.com).

1 Este artigo é extensivamente baseado na dissertação de mestrado do autor, apresentada em 2007 ao Programa de Pós-Graduação em Relações Internacionais San Tiago Dantas - PUC-SP/UNESP/UNICAMP - entitulada O Pensamento Neoconservador em Política Externa nos Estados Unidos.
} 
detalharem posicionamentos, maior o risco de se negligenciarem posicionamentos distintos entre os neoconservadores.

No entanto, da mesma forma, todas as correntes de pensamento são caracterizadas por um determinado conjunto de idéias que permitem a sua identificação e a sua distinção em relação a outros conjuntos de idéias, algo que se pode classificar como um mínimo denominador comum. É esse denominador que se pretendeu buscar na identificação dos temas a serem explorados nesse artigo.

Ou seja, pretende-se apresentar um conjunto de princípios básicos que poderia servir como um panorama geral do pensamento neoconservador, mas que não necessariamente determina a posição dos neoconservadores acerca de assuntos específicos em política externa, pois isso seria retirar a possibilidade de debates e divergências dentro do próprio neoconservadorismo.

Além disso, cabe observar que muitos dos temas não são exclusividade do pensamento neoconservador, estando presentes de forma dispersa em outras linhas de pensamento de política externa nos Estados Unidos, mesmo porque o neoconservadorismo não está de forma alguma totalmente desconectado das tradições do país nesse campo ${ }^{2}$.

Entretanto, acredita-se que o conjunto das partes apresentadas constitui um todo que parece suficiente para distinguir a abordagem neoconservadora em política externa de outras posiçôes consagradas dentro do espectro político norte-americano.

Destarte, identificaram-se e denominaram-se quatro temas essenciais do pensamento neoconservador em política externa, constantemente presentes de alguma forma desde o seu aparecimento. São eles: unilateralismo, internacionalismo não-institucional, democracia e poder militar. Trata-se de denominações genéricas que ensejam outros subtemas importantes a serem considerados dentro dos temas ora apresentados. Por exemplo, ao explorar a discussão sobre o unilateralismo, tópicos como hegemonia e unipolaridade serão considerados; tal como o tema da democracia leva à discussão sobre a importância do elemento moral no neoconservadorismo.

Destaque-se que nenhum dos temas subsiste separadamente dos demais na verdade, os quatro se interconectam e, mais do que isso, são conseqüência um do outro. Ou seja, uma postura de política externa baseada em fatores morais pode levar a um unilateralismo, que, por sua vez, necessariamente dispensaria o apoio de instituiçôes internacionais que, para sobreviver, necessitaria de um intenso suporte militar.

2 Esse é um importante debate que, aparentemente, permanece em aberto, e deverá ser mais bem tratado em pesquisas futuras. Para uma abordagem que enfatiza fatores de continuidade nas políticas defendidas pelos neoconservadores ver, por exemplo, GADDIS, John Lewis. Surprise, security, and the American experience. Cambridge, MA: Harvard University Press, 2004. Para uma avaliação do neoconservadorismo como ruptura na tradição norte-americana de política externa ver, por exemplo, DAALDER, Ivo H.; LINDSAY, James M. America unbound: the Bush revolution in foreign policy. Washington, DC: Brookings Institution Press, 2003. 
A divisão presentemente sugerida pretende servir apenas como instrumento didático a fim de enfatizar cada componente e organizar melhor a discussão. Sempre que possível, procurar-se-á contrastar como o neoconservadorismo se insere em cada tema em relação a outras posiçôes de política externa nos Estados Unidos a fim de tentar compreender a sua especificidade.

\section{Internacionalismo não-institucional}

O primeiro elemento que salta aos olhos no pensamento neoconservador em política externa é o seu ativo internacionalismo. Nesse sentido, os neoconservadores encontram-se claramente no extremo oposto dos que pregam uma postura isolacionista. Por outro lado, o neoconservadorismo também se choca com duas importantes abordagens em política externa no universo político norte-americano, que também são, em maior ou menor medida, internacionalistas: o realismo e o liberal internacionalismo.

Uma distinção importante entre a abordagem neoconservadora e a liberal internacionalista é que, se por um lado, os neoconservadores destacam a natureza hobbesiana das relações internacionais, os liberais internacionalistas partem de uma visão mais otimista, o que leva a atitudes distintas no momento da avaliação de onde intervir.

Desse modo, normalmente o internacionalismo liberal tende a favorecer mais as intervenções de caráter humanitário, sem aparente conexão com a segurança imediata dos Estados Unidos, ao passo que o neoconservadorismo utiliza critérios mais relacionados ao poder e à segurança norte-americanos. Logo, o internacionalismo neoconservador não é universalista em sua acepção, mas é um internacionalismo de caráter nacionalista, que deriva de um sentimento patriótico, a partir da constatação da suposta singularidade dos Estados Unidos frente às demais nações.

Para Huntington, "o patriotismo é uma - talvez a principal - virtude conservadora primordial. Os conservadores conferem sua mais elevada lealdade

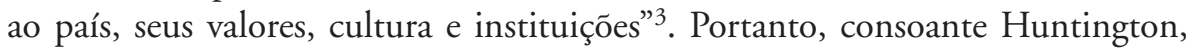
uma característica distintiva do internacionalismo conservador em contraste com o internacionalismo liberal é que aquele defende um "nacionalismo robusto que reafirma algumas verdades básicas: os Estados Unidos são uma nação religiosa; o patriotismo é uma virtude, universalismo não é americanismo; nacionalismo não é isolacionismo"' .

Assim, na política externa, o neoconservadorismo busca unir uma postura internacionalista a um sentimento nacionalista, "transcendendo a antiga polaridade isolacionista-internacionalista" em que o isolacionismo "sempre foi

3 HUNTINGTON, Samuel. Robust Nationalism. The National Interest, New York: The Nixon Center, n. 58, inverno de 1999/2000, p. 37.

4 Ibidem, p. 39 
nacionalista em seu temperamento, enquanto que os internacionalistas sempre operaram a partir de um ponto de vista global"5.

Dessa maneira, fica clara a diferença existente entre as posturas do internacionalismo liberal, que tende a um universalismo, e a do internacionalismo conservador, de caráter nacionalista. No entanto, resta determinar se existe diferença significativa entre um conservadorismo internacionalista e o neoconservadorismo.

Apesar de algumas análises tratarem como sinônimos, acredita-se poder apontar algumas distinções entre o que seria um conservadorismo internacionalista e a postura normalmente defendida no âmbito do neoconservadorismo. A primeira delas é que os conservadores normalmente aproximam-se mais da visão realista, ao passo que os neoconservadores buscam explicitamente um afastamento em relação ao realismo.

Outradistinçãoimportanteéque, em comparação comoneoconservadorismo, o conservadorismo norte-americano adota uma postura mais defensiva no plano internacional, em contraposição a uma postura pró-ativa defendida pelos neoconservadores que deriva de um alargamento do entendimento do que seria o interesse nacional dos Estados Unidos. A postura neoconservadora nesse aspecto é sintetizada por Irving Kristol, ao afirmar que os Estados Unidos deveriam perseguir "uma política de ação ao invés de reação"6.

A característica internacionalista do neoconservadorismo fica evidente quando se examinam as discussões que se estruturavam na década de 1990 acerca de qual deveria ser o papel dos Estados Unidos após o fim da Guerra Fria. Enquanto muitos grupos defendiam uma redução significativa na presença internacional dos Estados Unidos, a resposta neoconservadora era que o momento deveria ser aproveitado para avançar os interesses e os princípios norte-americanos ao redor do globo. Para Robert Kagan e William Kristol:

Tendo derrotado o "império do mal", os Estados Unidos desfrutam de predominância estratégica e ideológica. $\mathrm{O}$ primeiro objetivo da política externa norte-americana deveria ser preservar e aumentar essa predominância reforçando a segurança dos Estados Unidos, apoiando seus amigos, avançando seus interesses, e defendendo os seus principios pelo mundo todo [grifo nosso] $]^{7}$.

Portanto, do ponto devista dos neoconservadores, os Estados Unidos deveriam assumir definitivamente o papel de "superpotência", o que conseqüentemente significaria um maior envolvimento nos conflitos internacionais. De acordo com essa visão, sendo a superpotência uma nação com pretensões e interesses em todas as partes do globo, o envolvimento com assuntos externos seria não apenas desejoso, mas necessário.

5 KRISTOL, Irving. Reflections of a neoconservative. New York: Basic Books, 1983, p. 245.

6 KRISTOL, Irving. The old world needs a new ideology. Wall Street Journal, New York, 1 de abril de 1985.

7 KAGAN, Robert; KRISTOL, William. Toward a neo-reaganite foreign policy. Foreign Affairs, New York: Council on Foreign Relations, vol. 5, n. 4, julho/agosto de 1996, p. 20. 
Deste modo, com o desaparecimento da União Soviética e com o fim do conflito bipolar, o neoconservadorismo encontraria espaço para avançar ainda mais em seu argumento. Ainda em 1986, Kristol já destacava que uma decisão norte-americana de não se envolver em conflitos internacionais teria conseqüências tão significativas quanto a opção contrária ${ }^{8}$.

Uma década depois, com a Guerra Fria já terminada, Kagan e Kristol argumentavam, conforme citado acima, que os Estados Unidos deveriam reforçar sua predominância no plano internacional através de um envolvimento ativo em questôes internacionais ${ }^{9}$. E, em 2000 - antes portanto dos ataques terroristas do ano seguinte - esses autores levariam o argumento ainda mais adiante, defendendo que os Estados Unidos deveriam estar preparados para agir, se necessário, de forma que prevenisse que ameaças potenciais se concretizassem.

$\mathrm{Na}$ avaliação dos autores, os Estados Unidos deveriam adotar uma postura internacional que seja "mais, do que menos inclinada a agir quando as crises se rompem, e preferencialmente antes de elas se romperem. Esse é o padrão de uma superpotência global que quer moldar o ambiente internacional de forma vantajosa para si” (grifo nosso) ${ }^{10}$. Note-se que essa argumentação é parte importante na justificativa de guerras preventivas, conforme se abordará adiante.

Logo, uma das principais características do pensamento neoconservador em política externa é justamente o seu caráter eminentemente internacionalista, marcado pela defesa de um envolvimento ativo nos assuntos globais, a partir da crença de que os Estados Unidos têm a responsabilidade, a capacidade e o interesse na construção de uma ordem internacional que satisfaça os seus objetivos. Por conseguinte, o argumento neoconservador tenderá fortemente a defender uma política externa "ativa" em contraste com o que é enxergado como uma política externa "reativa" ou "defensiva".

Tal característica, no entanto, também poderia caracterizar em certa medida a postura liberal internacionalista. Entretanto, surge uma importante diferença: ao passo que o liberal internacionalismo caracteriza-se por ser abalizado majoritariamente por instituições supranacionais, o internacionalismo neoconservador nutre profunda desconfiança por tais arranjos institucionais.

Por essa razão, escolhe-se caracterizar esse tipo de internacionalismo como um "internacionalismo não-institucional". É importante destacar que esta se trata de uma, entre outras denominações possíveis. Uma designação alternativa poderia ser "internacionalismo nacionalista".

Ela teria a vantagem de destacar o fato de o internacionalismo neoconservador não ter um caráter humanitário, mas sim tratar-se de um tipo de internacionalismo

8 KRISTOL, Irving. Global unilateralism and entangling alliances. Wall Street Journal, New York, 3 de fevereiro de 1986.

9 KAGAN, Robert; KRISTOL, William. Toward a neo-reaganite foreign policy. Op. cit.

10 KAGAN, Robert; KRISTOL, William. Present dangers: crisis and opportunity in American foreign and defense policy. San Francisco: Encounter Books, 2000, p. 14. 
que busca uma íntima conexão com os interesses dos Estados Unidos que, por sua vez, corresponderiam também, dentro da ótica neoconservadora, aos interesses dos demais países democráticos. Outra denominação plausível seria "internacionalismo unilateral", mas seria menos acurada, visto que do ponto de vista neoconservador uma ação multilateral pode ser feita através de coalizões ad hoc e, portanto, dispensar a intervenção de organizações internacionais (tratado a seguir).

Charles Krauthammer é bem claro a respeito da posição neoconservadora nesse sentido ao afirmar que "a construção de 'coalizōes de voluntários' ad hoc dificilmente qualifica-se como unilateralismo só porque não tem um secretariado em Bruxelas ou no East River"11.

Ressalte-se que os conservadores norte-americanos em geral tendem a ter uma posição mais cética em relação aos organismos internacionais. Nau destaca que "nenhum grupo conservador dá a ONU papel de destaque" e essa seria uma linha clara de divisão em relação aos liberais ${ }^{12}$. Huntington também sublinha tal distinção ao apontar que o nacionalismo é uma característica distintiva dos conservadores norte-americanos que, portanto, "resistem a intromissóes na soberania nacional por parte de organizaçōes internacionais, cortes ou regimes"13.

Entretanto, ainda que a afirmação de que um certo tipo de internacionalismo não-institucional seja uma característica dos conservadores norte-americanos em geral, no caso específico dos neoconservadores tal predicado é especialmente verdadeiro, sobretudo se se considera a questão dos limites da ação internacional que, de certa maneira, diferencia os neoconservadores dos conservadores de orientação mais internacionalista, conforme mencionado acima.

Com isso, já em 1983, Irving Kristol referiu-se aos "inúmeros tratados, convençôes e alianças" internacionais como uma "piscina de areia movediça" ${ }^{14} \mathrm{e}$ ironizou a Organização dos Estados Americanos (OEA) referindo-se a ela como "uma espécie de mini ONU onde podemos ser derrotados em apenas três línguas, economizando assim dinheiro com tradutores" 15 .

Contudo, a crítica dos neoconservadores às organizações internacionais tornar-se-ia ainda mais aguda após o final da Guerra Fria, a partir de três argumentos principais: uma alegada falta de legitimidade por parte de tais organizaçóes, os eventuais entraves colocados para uma atuação internacional norte-americana mais contundente, e a percepção de que muitos organismos internacionais servem de fórum para países hostis aos Estados Unidos. A partir desses argumentos, o

11 KRAUTHAMMER, Charles. Democratic realism: an American foreign policy for a unipolar world. Washington DC: The AEI Press, 2004, p. 12. "Coalizão de voluntários" é a nossa tradução para o termo "coalition of the willing". East River é uma referência de Krauthammer à região de Nova Iorque onde fica a sede da Organização das Nações Unidas (ONU).

12 NAU, Henry. No enemies on the right. The National Interest, New York: The Nixon Center, n. 78, inverno de 2004, pp. 23-24.

13 HUNTINGTON, op. cit., p. 38

14 KRISTOL, Irving. Refletions of a neoconservative. Op. cit., p. 227.

15 Ibidem, p. 229. 
neoconservadorismo busca minar as duas principais justificativas para e existência de tais organismos - sua eficácia e sua legitimidade.

$\mathrm{O}$ argumento da falta de legitimidade dos organismos internacionais baseiase principalmente na crença neoconservadora da democracia como valor supremo e na conseqüente observação de que muitos dos países participantes de organizações internacionais não são democracias. Logo, do ponto de vista neoconservador, seria moralmente ilegítimo exigir que os Estados Unidos necessitem da chancela de organismos internacionais, compostos em parte por nações não-democráticas, para poder agir internacionalmente na defesa de seus interesses. Krauthammer desenvolve esse argumento em relação ao Conselho de Segurança da ONU:

É impossível entender a lógica moral pela qual a aprovação do Conselho de Segurança confere legitimidade moral para esse ou qualquer outro empreendimento. Como as bênçãos dos carniceiros da Praça Tiananmen, que detém o assento chinês no Conselho, empresta autoridade moral para qualquer coisa, quanto mais a invasão de outro país? ${ }^{16}$

Em um artigo defendendo a retirada dos Estados Unidos da ONU, Krauthammer chama a atenção para o que chama de "idealismo" e "ingenuidade" dos estadistas envolvidos na sua fundação ${ }^{17}$. Para o autor, essa organização, considerada como uma "instituição de papel" e "dispensável", é um obstáculo inclusive para a aplicação de normas internacionais, dada a alegada inexistência de alguém que faça cumprir tais normas.

É interessante observar que a referência à idéia de "papel" é relativamente comum entre os neoconservadores, referindo-se a arranjos institucionais e legislações internacionais que na sua visão estariam afastados da realidade do poder. Boot, por exemplo, caracteriza o neoconservadores como depositando "sua fé não em pedaços de papel, mas no poder, especificamente no poder americano"18.

Da mesma forma, Krauthammer considera que a divisão fundamental no debate sobre a política externa nos Estados Unidos é "a questão sobre o que é, e o que deveria ser a base fundamental das relaçôes internacionais: papel ou poder" 19 .

Se com o final da Guerra Fria as críticas dos neoconservadores às organizações internacionais tornaram-se ainda mais incisivas, o período após 11 de setembro de 2001 serviu para reforçar essa contundência. A questão agora não era apenas o fato da ONU ser encarada como um entrave no avanço os interesses da grande potência, mas agora como um obstáculo à própria defesa da segurança nacional norte-americana.

16 KRAUTHAMMER, Charles. The unipolar moment revisited. The National Interest, New York: The Nixon Center, 22 de dezembro de 2002.

17 KRAUTHAMMER, Charles. Why the US should bail out of the UN. The New Republic, Washington, DC: [s.n], 24 de agosto de 1987.

18 BOOT, Max. Myths about neoconservatism. IN: STELTZER, Irwin (Org.). The neocon reader. New York: Grove Press, 2004, p. 49.

19 KRAUTHAMMER, Charles. A new type of realism. The National Interest, New York: The Nixon Center, inverno 2002/2003, p. 13. 
Frum e Perle, por exemplo, avaliavam que a ONU ter-se-ia tornado, na melhor das hipóteses, irrelevante e, na pior, um obstáculo na ofensiva norteamericana contra o terrorismo transnacional ${ }^{20}$. Assim, a partir do ponto de vista de que a denominada "guerra ao terrorismo" requereria ações rápidas por parte dos Estados Unidos, as deliberações do Conselho de Segurança da ONU passaram a ser encaradas como um obstáculo adicional a tais ações e, por extensão, um obstáculo à própria segurança nacional norte-americana.

\section{Unilateralismo}

O primeiro ponto a notar ao se abordar a questão do unilateralismo é que essa é uma opção sempre presente na política externa norte-americana, ainda que no plano retórico os estadistas mantivessem o discurso multilateral. Logo, o unilateralismo na política externa norte-americana não constitui exatamente uma novidade, especialmente se se considera sua manifestação dentro do campo conservador.

Entretanto, aparentemente nenhum grupo político dá tanto peso a essa opção, inclusive no plano retórico, como os neoconservadores, cuja preferência pelo unilateralismo é explicitamente declarada. Soma-se a isso o fato de que, frequentemente, o discurso acerca do unilateralismo no universo político norteamericano relaciona-se de forma mais estreita com aqueles que defendem uma postura mais isolacionista, de caráter defensivo.

Deste modo, a postura internacionalista preconizada pelos neoconservadores adiciona um elemento fundamental à ação unilateral, vista como uma opção necessária para uma potência com pretensões globais. Nessa direção, Krauthammer avalia que "a virtude do unilateralismo não é apenas que ele permita a ação. Ele força-a" 21 . O unilateralismo neoconservador diferenciase, assim, do unilateralismo isolacionista notadamente em razão de seu caráter internacionalista, que se conecta intimamente com o entendimento do que seria $\mathrm{o}$ interesse nacional norte-americano.

Para Krauthammer, o unilateralismo defendido pelos neoconservadores, pode ser classificado como um "novo unilateralismo"22. De acordo com o autor, o unilateralismo é normalmente associado aos isolacionistas que por sua vez pouco se preocupariam com o uso do poder americano para "fins globais", mas simplesmente no sentido de defender os interesses norte-americanos a partir de um entendimento considerado "estreito" do interesse nacional.

Dessa forma, trata-se de um unilateralismo com interesses globais, visando a manutenção e preservação da ordem internacional estabelecida através do

20 FRUM, David; PERLE, Richard. UN should change, or US should quit. Los Angeles Times, Los Angeles, 23 de janeiro de 2004, p. B13.

21 KRAUTHAMMER, Charles. The unipolar moment revisited. Op. cit.

22 KRAUTHAMMER, Charles. A new type of realism. Op. cit. 
apoio ativo à democracia por parte dos Estados Unidos. Note-se que, ao falar em unilateralismo, os neoconservadores referem-se principalmente às alianças formais e institucionais formadas pelos Estados Unidos notadamente durante a Guerra Fria.

Kristol entende que o unilateralismo não significa "retirar-se de toda e qualquer aliança" 23 , mas livrar os Estados Unidos das que, no seu entendimento, impediriam uma ação mais livre por parte desse país, classificadas pelo autor como "entangling alliances" 24 . Krauthammer pondera que agir unilateralmente não significa necessariamente agir sozinho, mas "não permitir tornar-se refém de outros"25.

Por conseguinte, o entendimento neoconservador parece não passar pela constatação de que os Estados Unidos devam necessariamente agir sozinhos, mas de que essa é uma opção que não deve ser descartada a priori. A formação das alianças é definida em caráter ad hoc de acordo com o objetivo determinado.

Portanto, a coalizão é formada a partir da definição da missão, estando aquela subordinada a esta, ou seja, "a missão determina a coalizão" ${ }^{26}$, e não o contrário. Para Krauthammer, essa abordagem significa que aqueles que estiverem dispostos a participar da coalizão deverão ser recrutados "apenas para ajudar a cumprir nossa missão. A missão vem primeiro e nós a definimos"27.

A defesa neoconservadora do unilateralismo baseia-se principalmente em dois argumentos. O primeiro, conforme já tratado na seção anterior, refere-se a uma alegada falta de legitimidade de organismos supranacionais. O segundo argumento fundamenta-se na premissa de que o unilateralismo é necessário para aumentar o raio de ação da superpotência no plano internacional.

Nesse sentido, em sua crítica às "entangling alliances", Kristol assevera que, para uma superpotência, alianças desse tipo concorrem para inibir a tomada de ação por sua parte no momento em que entender conveniente ${ }^{28}$. Para Krauthammer a opção pelo multilateralismo acarreta uma "obsessão com convenções, protocolos, legalismos", cujo efeito é "conter o poder americano". Desse ponto de vista, o objetivo dos defensores do multilateralismo seria "amarrar Gulliver com milhares de cordas" 29 .

O unilateralismo é visto de tal modo como uma demonstração de força e poder ao passo que o multilateralismo é enxergado como uma ferramenta à

23 KRISTOL, Irving. Global unilateralism and entangling alliances. Op.cit.

24 Deixa-se no original, pois não se encontrou uma tradução satisfatória para o termo, que ficou famoso após o discurso inaugural de Thomas Jefferson em 1801. Uma sugestão, conforme adotada por Sá Barbosa e Bezerra, seria "alianças que nos embaracem" (SCHLESINGER JR, 1992: 65). Apesar de o termo não aparecer explicitamente no famoso discurso de despedida de George Washington, a mesma idéia também já estava presente ali - sempre tendo em mente a relação com as potências européias. O que outrora havia sido interpretado como uma recomendação ao isolacionismo, hoje parece haver um entendimento de que tal conselho de fato relaciona-se mais com o unilateralismo. Nesse sentido ver, por exemplo, McDougall (1997: 39-56).

25 KRAUTHAMMER, Charles. A new type of realism. Op. cit.

26 Frase atribuída originalmente ao ex-Secretário de Defesa norte-americano, Donald Rumsfeld.

27 KRAUTHAMMER, Charles. The unipolar moment revisited. Op. cit.

28 KRISTOL, Irving. Global unilateralism and entangling alliances. Op. cit.

29 KRAUTHAMMER, Charles. Democratic realism. Op. cit, p. 6. 
disposição de países menos poderosos. Com isso, o neoconservadorismo busca justificar especialmente a oposição de países aliados ao unilateralismo norteamericano, sobretudo na Europa. Para Kagan (2003), os Estados Unidos devem ocasionalmente agir sem o apoio de aliados europeus "não em razão de paixão pelo unilateralismo, mas só porque, devido a uma fraca Europa que se afastou do poder, os Estados Unidos não tem opção além de agir de maneira unilateral"30. De acordo com esse autor, a hostilidade dos europeus ao unilateralismo representa uma defesa de seus próprios interesses e mecanismos como o Conselho de Segurança das Nações Unidas seriam "o substituto do poder que lhes falta" ${ }^{31}$. Para Perle, "dada a inadequada capacidade militar dos europeus, a inabilidade em usar a força transforma-se facilmente em repugnância ao uso da forç" ${ }^{32}$.

\section{Democracia}

A forte conexão entre política externa e democracia nos Estados Unidos seguramente constitui uma tradição deste país desde os seus primórdios. A questão da democracia sempre esteve presente como um elemento central na política externa norte-americana, sendo que a principal diferença detectada pela literatura é em relação a qual o papel desempenhado pelos Estados Unidos na defesa dos valores democráticos - apresentar-se como exemplo a ser seguido ou promover ativamente a democracia no plano internacional.

De forma geral, o conservadorismo tradicional tende a advogar a primeira alternativa. Por outro lado, o internacionalismo liberal encontra-se mais próximo da segunda e nesse sentido aproxima-se da posição neoconservadora.

No entanto, a defesa neoconservadora de que os Estados Unidos devem atuar ativamente para difundir a democracia no mundo, passa pela crítica ao internacionalismo liberal, visto como um "humanitarianismo cosmopolita" que defenderia a democracia apenas em nome da própria democracia e dos direitos humanos. Os neoconservadores, por sua parte, enfatizam de modo mais vigoroso uma ligação intrínseca entre a promoção da democracia e o interesse nacional americano, a partir do entendimento de que essa estratégia é essencial para garantir a segurança do país e reforçar sua supremacia no cenário internacional.

Portanto, a partir da conexão entre democracia e segurança, os neoconservadores encaram a primeira sob dois aspectos fundamentais. Como um imperativo moral e assim buscam afastar-se da abordagem realista. Segundo, eles avaliam que a promoção da democracia deve ser parte crucial da estratégia de segurança norte-americana, pois essa seria não apenas um imperativo moral, mas

30 KAGAN, Robert. Do paraíso e do poder: os Estados Unidos e a Europa na nova ordem mundial. Rio de Janeiro: Rocco, 2003, p. 100.

31 Ibidem, p. 43.

32 PERLE, Richard. Is the UN the only institution that can legitimize force? New Perspectives Quarterly, Boston: Blackwell Publishing, vol. 20, n. 1, inverno de 2003, p. 69. 
também "a melhor forma de assegurar a manutenção de uma ordem mundial pacífica e próspera" 33 .

Quanto ao primeiro aspecto, o neoconservadorismo busca resgatar a idéia presente desde a independência dos Estados Unidos "de que a liberdade individual é um absoluto moral, e um sistema de governo que realça a liberdade individual é moral e praticamente superior a todos os outros" 34 .

Desse modo, o pensamento neoconservador avalia que, dada a uma alegada universalidade dos propósitos morais, as relaçôes internacionais tornam-se um espaço onde os julgamentos morais são não apenas possíveis, mas necessários. Podhoretz explicita essa visão ao destacar a "necessidade e a possibilidade de julgamento moral no terreno da política internacional" 35 .

Kagan e Kristol defendem uma "remoralização" da política externa norteamericana a partir "da crença americana de que os princípios da Declaração de Independência não são apenas escolhas de uma cultura particular, mas são verdades universais, duradouras e 'auto-evidentes" (grifo nosso) ${ }^{36}$.

Nesse ponto, os autores fazem uma crítica aos conservadores tradicionais, que pregariam "a importância de se preservar os elementos centrais da tradição ocidental no plano doméstico", mas ao mesmo tempo professariam uma "indiferença ao destino dos princípios norte-americanos no plano internacional" e avaliam essa postura como "uma inconsistência cujo resultado só pode ser o desgaste do coração do conservadorismo" ${ }^{37}$. Assim, seria natural, a partir desse ponto de vista, que os Estados Unidos assumissem uma postura de "missão civilizadora" no mundo.

No que diz respeito à conexão entre democracia e segurança, cuja presença no discurso neoconservador é central, acredita-se ser importante uma breve exposição acerca do que ficou conhecido como as teorias da "paz democrática" que estimularam diversos debates, notadamente durante os anos 1990, a partir da constatação de uma aparente inexistência de guerras entre os países democráticos.

Doyle avalia que a partir do século XVIII estabeleceu-se - entre o que o autor chama de "sociedades liberais" - uma "zona de paz", nos moldes kantianos de uma "federação pacífica" 38 .

Para Layne ${ }^{39}$, a teoria da paz democrática é mais uma proposição do que uma teoria propriamente dita e baseia-se em duas crenças principais. A primeira é a de

33 STELTZER, Irwin (Org.). The neocon reader. New York: Grove Press, 2004, p. 10.

34 SELDEN, Zachary. Neoconservatives and the Americam mainstream. Policy Review, Stanford: Hoover Institution, n. 104, abril/maio de 2004, p. 30.

35 PODHORETZ, Norman. World War IV: how it started, what it means, and why we have to win. Commentary, New York: AJC, vol. 118, n. 2, setembro de 2004, p. 27.

36 KAGAN, Robert; KRISTOL, William. Toward a neo-reaganite foreign policy. Op. cit.

37 Idem.

38 DOYLE, Michael W. Liberalism and world politics. American Political Science Review, Washington, DC: APSA, vol. 80, n. 4, dezembro de 1986.

39 LAYNE, Christopher. The unipolar illusion: why new great powers will rise. International Security, Cambridge, MA: The MIT Press, vol. 17, n. 4, pp. 5-51, primavera de 1993. 
que as democracias não lutam entre si. A segunda é que quando as democracias entram em conflito, apenas raramente ameaçam o uso da força, pois isso seria considerado ilegítimo.

As teorias que buscam explicações para esse fenômeno, de acordo com o autor, dividir-se-iam em duas vertentes. A primeira explicaria a aparente abstenção de guerras entre as democracias em virtude de constrangimentos institucionais. Owen classifica as teorias que se baseiam nessa hipótese como "estruturais" ${ }^{\circ}$.

A segunda hipótese enfatizaria questōes como as normas e a cultura democrática que impediriam os estados democráticos de irem à guerra com outras democracias. Para Owen, essas teorias também podem ser classificadas como "normativas" e baseiam-se na premissa de que do ponto de vista das democracias seria injusto ou imprudente entrar em guerra com outras democracias ${ }^{41}$.

Essa segunda vertente é a mais aceita pelos neoconservadores e é o que dá suporte a afirmações como a de Krauthammer de que a democracia seria um meio indispensável para promover a segurança dos Estados Unidos, visto que "as democracias são inerentemente mais amistosas em relação aos Estados Unidos, menos beligerantes em relação a seus vizinhos e geralmente mais inclinadas para a paz" ${ }^{\prime 2}$.

É importante destacar que o que os teóricos da paz democrática entendem como democracia é a de caráter liberal. Owen define uma democracia liberal como "um estado que encarna as idéias liberais, onde o liberalismo é a ideologia dominante, e onde os cidadãos têm influência sobre as decisões de guerra" ${ }^{43}$.

$\mathrm{O}$ autor acrescenta que o liberalismo distingue o Estado de acordo com o tipo de regime, ao passo que o realismo, de acordo com as capacidades. Desse modo, Estados liberais seriam vistos como aliados e os não-liberais, como potencialmente perigosos. Portanto, a partir do entendimento de que os países liberais não entram em guerra uns com os outros, e, por outro lado, de que os países que não são vistos como democracias liberais são percebidos como potenciais ameaças, a conclusão é que o nível de segurança internacional aumenta conforme aumenta a quantidade de democracias no mundo.

Essa argumentação abre o caminho para a idéia de "mudança de regime" ("regime change"), cuja presença no discurso neoconservador é de capital importância. Tal conceito baseia-se na proposição de que os Estados Unidos devem utilizar todos os meios disponíveis para pressionar a transformação de países nãodemocráticos em democracias liberais. Aqui, um exemplo frequentemente citado é a transformação da Alemanha e do Japão a partir do suporte dos Estados Unidos após a Segunda Guerra Mundial. Para Podhoretz, o fato de que "os Estados Unidos

40 OWEN, John M. How liberalism produces democratic peace. In: BROWN, Michael E. et al. Theories of war and peace. Cambridge, Massachusetts: The MIT Press, pp. 137-175, 2000.

41 Idem.

42 KRAUTHAMMER, Charles. Democratic realism. Op. cit, p. 15.

43 OWEN, op. cit., p. 139 
conseguiram em apenas uma década transformar tanto a Alemanha Nazista como o Japão Imperial em democracias capitalistas" demonstraria que isto poderia ser feito em outras regiōes do mundo, contrariando os que acreditariam que "a democracia e o capitalismo poderiam desenvolver-se apenas num solo cultivado por séculos" ${ }^{4}$.

Kaplan aponta para previsões anteriores à reconstrução do Japão e da Alemanha que afirmavam que esses países não seriam culturalmente aptos para exercer a democracia, a fim de contestar o que seriam argumentos semelhantes acerca do Oriente Médio ${ }^{45}$.

Destaque-se que o otimismo demonstrado por grande parte dos neoconservadores em relação às condições para a promoção da democracia independentemente do país é contrabalançado internamente por nomes como Paul Wolfowitz. Para ele, "alguns regimes são mais abertos a mudanças que outros" e os exemplos de Alemanha e Japão na Segunda Guerra não se aplicam necessariamente a outras sociedades e circunstâncias particulares de cada país devem ser levadas em consideração, visto que "condiçôes econômicas e sociais podem preparar melhor alguns países para a democracia que outros" ${ }^{\prime 6}$.

Kristol e Kagan condensam os dois argumentos neoconservadores apresentados aqui em defesa da promoção da democracia - imperativo moral e conexão entre democracia e segurança em prol da sustentação da supremacia norte-americana e seu corolário (mudança de regime) - no trecho destacado a seguir:

A política externa norte-americana deveria ser informada por um propósito moral claro, baseado no entendimento de que seus objetivos morais e seus interesses nacionais fundamentais estão quase sempre em harmonia. Os Estados Unidos não atingiram a presente posição de força praticando uma política externa de viva e deixe viver, nem passivamente esperando as ameaças surgirem, mas promovendo ativamente afora os princípios de governança americanos - democracia, mercados livres, respeito pela liberdade [...] E algumas vezes isso significa não apenas apoiar os amigos dos Estados Unidos e pressionar suavemente outras nações, mas perseguir ativamente políticas - no Irã, em Cuba e na China, por exemplo que tenham a intenção última de efetuar uma mudança de regime. Em qualquer caso, os Estados Unidos não deveriam cegamente 'fazer negócio' com qualquer nação, independente de seu regime [grifo nosso] ${ }^{47}$.

Conseqüentemente, seria inútil a tentativa de incluir nações não-democráticas em acordos internacionais como forma de evitar, por exemplo, a proliferação

44 PODHORETZ, Norman. Op. cit., p. 47

45 KAPLAN, Lawrence. Springtime for realism. The New Republic, Washington, DC: [s.n], 21 de junho de 2004. 46 WOLFOWITZ, Paul. Statesmanship in the new century. In: KAGAN, Robert e KRISTOL, William (Org.). Present dangers: crisis and opportunity in American foreign and defense policy. San Francisco: Encounter Books, 2000, pp. 320-321.

47 KAGAN, Robert; KRISTOL, William. Present Dangers, p. 27. 
nuclear, visto que não haveria como fazer tais países “jogarem pelas existentes - o que quer dizer norte-americanas - regras do jogo" 48 .

A estratégia mais eficiente, a partir desse ponto de vista, seria "não a coexistência, mas a transformação" do próprio regime vigente nesses estados ${ }^{49}$. Portanto, constrói-se a argumentação que serve de suporte para intervenções, inclusive militares, em outros países, com o intuito último de efetuar uma mudança de regime em nações consideradas não-democráticas.

\section{Poder militar}

No início do século XX, o presidente norte-americano Theodore Roosevelt cunhou uma famosa frase que passaria a designar a política externa dos Estados Unidos naquele período como a "diplomacia do grande porrete" ("big stick diplomacy"). A frase completa, que Roosevelt afirmara ser de um provérbio africano, dizia: "Fale manso e carregue um grande porrete; você irá longe" ( "Speak softly and carry a big stick; you will go far").

A história encarregou-se de esquecer a parte da frase que diz respeito ao tom de voz para enaltecer a referência ao porrete. Do ponto de vista neoconservador, entretanto, o tom de voz também é algo importante, mas com o sinal invertido ao preconizado por Roosevelt, ou seja, os Estados Unidos devem carregar o porrete e falar grosso, à medida que isso serviria para dissuadir potenciais inimigos.

Assim, Kristol e Kagan ${ }^{50}$ defendem que os Estados Unidos devem "deixar claro que é inútil competir com o poder americano". Para esses autores, o fortalecimento do poderio militar norte-americano em todas as partes do globo teria o propósito de enviar uma "mensagem para potenciais inimigos: 'nem pense nisso"

A centralidade do poder militar no pensamento neoconservador só pode ser entendida a partir da compreensão de como ele relaciona-se com o uso da força como instrumento nas relações internacionais. Dessa forma, se para o pensamento liberal, as leis e as instituições devem garantir a ordem, sendo o uso da força considerado apenas como ultima ratio, para o pensamento neoconservador a mesma encontra-se em um patamar mais elevado na lista de prioridades.

Negligenciando a eficácia da legislação e das instituiçôes internacionais, preferindo confiar no "poder" e não no "papel" como base das relações internacionais, o neoconservadorismo entende que o uso da força é sempre uma alternativa a ser constantemente considerada.

A importância que o pensamento neoconservador dá ao poder militar é, entretanto, uma característica compartilhada com outras correntes conservadoras

48 Ibidem, p. 18.

49 Ibidem, p. 20.

50 KAGAN, Robert; KRISTOL, William. Toward a neo-reaganite foreign policy, Op. cit.

51 KAGAN, Robert; KRISTOL, William. Present dangers. Op. cit, p. 14. 
no universo político norte-americano. Para Nau, um dos princípios que une os conservadores norte-americanos é a crença de que, ao contrário do preconizado pelo liberalismo, o poder militar de uma determinada nação tem mais peso que seu poder econômico ou diplomático ${ }^{52}$.

Contudo, a ênfase na necessidade do fortalecimento militar frequentemente causa conflitos dentro dos círculos conservadores quando se leva em consideração a tendência do conservadorismo norte-americano em diminuir o papel do Estado, notadamente através de cortes de impostos.

Dado que a manutenção de um aparato militar é algo custoso, a necessidade de se mantê-lo choca-se com a diminuição dos recursos disponíveis pelo Estado. Esse conflito é resolvido normalmente de duas formas que acabam por caracterizar duas importantes manifestações do conservadorismo norte-americano: adota-se uma postura isolacionista, intervindo militarmente apenas nos casos de agressão direta, ou uma política externa normalmente associada a uma "prudência" preconizada pelo realismo, de intervenções específicas e forças armadas enxutas.

Todavia, conforme explicitado no início deste trabalho, os neoconservadores encontram-se no extremo oposto dos isolacionistas, defendendo uma política externa de caráter fortemente internacionalista, que considera o interesse nacional de uma grande potência e, especificamente, o interesse nacional dos Estados Unidos, como distinto do das demais nações, o que desemboca em uma defesa de intervenções constantes nas mais diversas partes do globo.

Além disso, o discurso neoconservador de aumento dos gastos militares é acompanhado, no plano interno, por uma defesa de um governo forte, bem como por uma assumida condescendência com o Estado de Bem-Estar Social, tão criticado pelas demais correntes conservadoras norte-americanas.

Em 1996, por exemplo, quando a Guerra Fria já havia acabado e os ataques terroristas de 2001 ainda eram uma realidade distante, Kagan e Kristol alertavam para os cortes nos gastos militares (caracterizando como uma "crise no orçamento militar") e defendiam uma volta aos níveis de gastos da Guerra Fria ${ }^{53}$.

$\mathrm{Na}$ mesma direção, Donald Kagan argumentava contrariamente à noção de "pausa estratégica" defendida por alguns analistas em virtude da evidente vitória dos Estados Unidos na Guerra Fria e avaliava que esse triunfo deveria ser encarado como uma oportunidade de aprofundar a vantagem estratégica norte-americana voltando aos níveis de gastos em defesa despendidos durante período bipolar ${ }^{54}$.

De acordo com o autor, isso seria especialmente importante à medida que os aliados norte-americanos na Organização do Tratado do Atlântico Norte (OTAN)

52 NAU, Henry. No enemies on the right. The National Interest, New York: The Nixon Center, n. 78, inverno de 2004 .

53 KAGAN, Robert; KRISTOL, William. Toward a neo-reaganite foreign policy, Op. cit.

54 KAGAN, Donald. Strenght and will: a historical perspective. In: KAGAN, Robert e KRISTOL, William (Org.). Present dangers: crisis and opportunity in American foreign and defense policy. San Francisco: Encounter Books, pp. 337-362, 2000. 
passavam por um período de cortes de gastos militares ainda maiores dos que os empreendidos pelos próprios Estados Unidos, de modo que, conforme Kagan, "as únicas forças que os Estados Unidos podem confiar que existirão e estarão prontas para deter ou opor-se a agressores regionais, são as nossas próprias" 55 .

Adicionalmente, o autor avaliava que no novo cenário pós-Guerra Fria os Estados Unidos deveriam estar preparados não apenas para deter um inimigo específico, "mas todo e qualquer possível futuro inimigo" 56 .

Após os ataques de 11 de setembro de 2001, o neoconservadorismo advogaria um pensamento estratégico ainda mais ousado - a idéia de guerra preventiva. Para Perle, os atentados de 11 de setembro teriam ensinado aos Estados Unidos a lição de que não poderiam mais cometer "o erro de esperar demais" antes de lidar efetivamente com as ameaças ${ }^{57}$.

É bem verdade que muitos neoconservadores de destaque já defendiam antes de 2001 que os Estados Unidos deveriam agir "preferencialmente antes do rompimento das crises" 58 , mas os ataques terroristas daquele ano reforçaram a revisão dos conceitos de contenção e dissuasão consagrados no período da Guerra Fria.

Do ponto de vista neoconservador, as estratégias dissuasórias do passado não seriam adequadas para lidar com "Estados Párias" ("Rogue States") e com organizaçôes terroristas de caráter global, porque a natureza dos atores é distinta. Mais do que nunca, a visão era a de que os Estados Unidos teriam o direito e a obrigação de exercer o seu poder no plano internacional, a fim de defender seus interesses e garantir sua segurança.

\section{Considerações finais}

Neste artigo se procurou identificar temas que são distintos do pensamento neoconservador e possuem algum grau de continuidade ao longo de sua existência. Caso tal tarefa se revelasse impossível, poder-se-ia concluir que o neoconservadorismo não seria um conjunto organizado de idéias, mas um mero amontoado de opiniōes passageiras. No entanto, ainda que não se tenha descartado a possibilidade de haver debates abundantes dentro do neoconservadorismo, pretendeu-se deixar de maneira clara a existência de uma determinada linha que permanece ao longo do tempo, ditada pelos seus mais destacados defensores e porta-vozes.

Portanto, procurou-se demonstrar, a partir do ponto de vista de seus participantes, que o pensamento neoconservador oferece um conjunto de idéias com uma visão específica acerca da condução política externa norte-americana.

55 Ibidem, p. 260.

56 Ibidem, p. 265.

57 PERLE, Richard. Op. cit.

58 KAGAN, Robert; KRISTOL, William. Toward a neo-reaganite foreign policy. Op. cit. 
Evitou-se deliberadamente empreender qualquer análise crítica, visto que isso representaria um desvio de foco da nossa tarefa principal neste artigo: apresentar, de forma resumida, os temas fundamentais do pensamento neoconservador em política externa, com vistas a contribuir para os futuros debates.

Recebido em 9 de abril de 2007 Aprovado em 30 de agosto de 2007

\section{Resumo}

A partir da utilização de diversos textos escritos pelos seus participantes, este artigo procurou identificar os elementos fundamentais que compõem o pensamento neoconservador em política externa. O critério de seleção dos temas ora apresentados foi baseado em dois fatores principais: sua relevância e sua continuidade ao longo do tempo.

\section{Abstract}

Using a wide array of texts written by neo-conservatives, this article identifies the basic elements of neoconservative thought in foreign policy. The selection of themes was based on two main factors: their relevance and their presence throughout a period of time.

Palavras-chave: Neoconservadorismo, política externa dos Estados Unidos Key words: Neo-conservatism, United States foreign policy 